\title{
AMARTYA SEN E O DIREITO À EDUCAÇÃO PARA O DESENVOLVIMENTO HUMANO
}

\author{
Ana Elizabeth Neirão Reymão ${ }^{1}$ \\ Karla Azevedo Cebolão ${ }^{2}$
}

\section{Resumo:}

O artigo discute a importância do investimento em educação como um dos pilares do desenvolvimento, conforme a abordagem teórica de Amartya Sen, que destaca a importância da realização pessoal dos indivíduos e da sua felicidade nesse processo, devendo as fontes de privação da liberdade serem removidas. A pesquisa é bibliográfica e conclui que a educação possui relevância central para o desenvolvimento humano, dado seu papel transformador das capacidades, para o exercício da autonomia e da liberdade, devendo o Estado fortalecer e proteger políticas públicas que assegurem o direito à educação.

Palavras-Chave: Educação; Desenvolvimento humano; Amartya Sen; Estado; Liberdade.

\section{AMARTYA SEN AND RIGHT TO EDUCATION FOR HUMAN DEVELOPMENT}

\begin{abstract}
:
This paper discusses the importance of investing in education for development, according to Amartya Sen's theory, which emphasizes the importance of the personal fulfillment of individuals and their happiness in this process. The sources of deprivation of liberty must be removed. This research is bibliographical and concludes that education has central relevance for human development, given its transforming role of capacities, for the exercise of autonomy and freedom, so the State should strengthen and protect public policies that ensure the education's right.
\end{abstract}

Keywords: Education; Human development; Amartya Sen; State; Freedom.

\footnotetext{
${ }^{1}$ Economista, professora da Faculdade de Economia da Universidade Federal do Pará (UFPA) e do Programa de Pós-Graduação em Direito do Centro Universitário do Pará (CESUPA). E-mail: bethrey@ uol.com.br

${ }^{2}$ Mestre em Direito, Políticas Públicas e Desenvolvimento Regional pelo Centro Universitário do Pará (CESUPA) e servidora do Tribunal de Contas do Estado do Pará. E-mail: karlacebolao@yahoo.com.br
} 


\section{INTRODUÇÃO}

O presente artigo discute a importância do investimento em educação como um dos pilares para alcançar o desenvolvimento, tomando-se como referência a abordagem teórica de Amartya Sen.

O texto legal de muitos países garante o direito de acesso, permanência e sucesso de seus cidadãos à educação escolar básica. O direito à educação é proclamado no artigo $6^{\circ}$ da Constituição Federal de 1988 como o primeiro direito social e o artigo 205 anuncia a educação como um direito de todos e dever do Estado e da família, devendo ser promovida e incentivada com a colaboração da sociedade, objetivando "o pleno desenvolvimento da pessoa, seu preparo para o exercício da cidadania e sua qualificação para o trabalho".

Desde a década de 1990, as discussões sobre esse tema ganharam espaço e destaque no ambiente acadêmico. Ao conceito de desenvolvimento foram incorporadas outras preocupações para além da renda, como a de sustentabilidade do meio ambiente e as que chamam atenção para uma nova forma de se entender o conceito de desenvolvimento humano. Esse conceito, em foco no presente estudo, passou a incorporar outras dimensões bem mais amplas e complexas, além das tradicionais medidas de renda e renda per capita, definidas a partir do produto interno bruto (PIB).

Dentre os fatores que podem ser levantados para explicar essa nova visão de desenvolvimento está a constatação das consequências adversas da atividade econômica no meio ambiente, o aumento dos índices de pobreza, o desemprego, a favelização e a precarização das condições de vida.

Compreendendo o desenvolvimento como resultado da expansão das capacitações humanas e a qualidade de vida das pessoas ligada à capacidade de cada um funcionar como ser humano que tem suas necessidades básicas de educação, saúde, habitação, nutrição, participação da vida em comunidade, respeito e outras atendidas, Sen (2000) apresenta-nos uma teoria que destaca a importância da realização pessoal dos indivíduos e da sua felicidade. As fontes de privação da liberdade têm que ser retiradas, viabilizando a liberdade de agir do ser humano. A educação, entre outros direitos sociais, gera os instrumentos e capacidades para o exercício da autonomia e da liberdade, tirando o indivíduo da absoluta pobreza, defende o autor. 
Nesse contexto, o Estado e a sociedade devem fortalecer e proteger essas capacidades, que podem ser potencializadas por políticas públicas de educação.

Em uma pesquisa bibliográfica e documental, revisitando a literatura do tema, o estudo apresentado é de abordagem qualitativa e o texto é estruturado em quatro partes. Após essa introdução, a seção a seguir discute o conceito de desenvolvimento na visão de Amartya Sen. Na seção três, reflete-se acerca do papel do Estado na efetivação do direito à educação e a importância dessa educação para o desenvolvimento humano. A seção final apresenta as principais conclusões do artigo.

\section{DESENVOLVIMENTO NA VISÃO DE AMARTYA SEN}

O conceito de desenvolvimento humano é central na teoria de Amartya Sen. Embora criticadas por muitos outros autores ${ }^{3}$, prevaleciam na literatura acadêmica as abordagens de desenvolvimento sobre uma ótica mais restrita, como as que o associam ao crescimento do produto interno bruto (PIB), aumento de rendas pessoais, industrialização ou avanço tecnológico.

Na teoria de Sen (2000), o desenvolvimento é alcançado a partir da expansão das capacitações humanas. Para ele, a vida humana é um conjunto de "fazeres e seres", também chamado de "funcionamentos", estando a qualidade de vida das pessoas associada ao acesso à capacidade de elas funcionarem como seres humanos.

Sob essa ótica, o aumento da renda e a expansão da produção devem ser considerados os meios, mas não os fins do desenvolvimento cujo objetivo é ampliar as escolhas dos indivíduos, permitindo-lhes um aumento no bem-estar, melhoria da qualidade de vida e das liberdades que desfrutam.

O crescimento econômico, ainda que importante, não pode ser um fim em si mesmo e o desenvolvimento acontece com a "expansão das liberdades reais que as pessoas desfrutam" (SEN, 2000, p. 17). É importante que as vidas das pessoas possam ser vividas para que

\footnotetext{
${ }^{3}$ Autores ligados às teorias de desenvolvimento local, como Reyes (2001), críticos da ênfase excessiva nos aspectos econômicos na discussão sobre o desenvolvimento, incorporam os aspectos sociais, políticos e territoriais no debate. Furtado (1974), trata o desenvolvimento econômico como mito, advertindo que a elevação de indicadores econômicos não repercute necessariamente de forma positiva na melhoria da qualidade de vida dos indivíduos em sociedade. Sachs (2004) introduz o conceito de ecodesenvolvimento, pregando uma forma de desenvolvimento em que há um atendimento de necessidades humanas fundamentais (materiais e intangíveis), promoção da autoconfiança (self-reliance) das populações envolvidas e cultivo da ecológica.
} 
consigam realizar seus projetos de vida, individual e coletivo, de forma satisfatória, daí que não se pode falar em desenvolvimento sem que o ser humano tenha liberdade para exercer sua qualidade de agente.

Para compreender a argumentação do autor, dois conceitos são fundamentais, o de capacidades (capabilities) e funcionamentos (functionings). Os funcionamentos são dados pelas atividades ou estados de existência importantes para os indivíduos possam levar o tipo de vida que valorizam, variando desde questões elementares, como estar alimentado e saudável ou, até mesmo, estar relacionado com outras questões mais complexas (SEN, 2000). Ou seja, inclui desde o atendimento das necessidades básicas de educação, saúde, habitação, nutrição adequada, até participar da vida em comunidade, ter respeito próprio e outros.

O conceito de capacidades (capabilities), por sua vez, relaciona-se às combinações alternativas de funcionamentos que podem ser realizados pela pessoa, refletem as habilidades que uma pessoa tem para executar ou alcançar os estados que considere desejáveis. São combinações alternativas de funcionamentos possíveis de realização por uma pessoa, explica Sen (2000), podendo ser definidas como o conjunto alternativo de funcionamentos exequível de cada ser humano.

Não há desenvolvimento sem que o ser humano seja o centro desse processo, advoga Sen (2000), daí a importância da realização pessoal dos indivíduos e da sua felicidade. Portanto, bem-estar e desenvolvimento dizem respeito ao fortalecimento de liberdades e à melhora de vida dos indivíduos, assumindo a felicidade humana um importante papel nesse processo, como destaca Pinheiro (2012, p. 12):

(...) o aumento da capacidade que tem a pessoa humana de atingir seu fim último, o seu bem, a sua felicidade.(...) desenvolvimento denota um processo complexo, cujos fins devem ser as pessoas mesmas, com seus almejados objetivos, estilos e qualidades de vida.

O fim último do desenvolvimento, o bem das pessoas, é associado à liberdade, isto é, à potência pessoal de conseguir a vida que deseja racionalmente. Nesse sentido a liberdade é pensada positivamente como poder, autonomia e autodeterminação do agente, bem como colocada no centro da abordagem do desenvolvimento como liberdade, desempenhando um duplo papel avaliativoconstrutivo e causal-instrumental no processo de desenvolvimento.

A liberdade, para Sen (2000), pode ser vista como o fim e o meio do desenvolvimento, em que tem papel constitutivo e instrumental. No que diz respeito ao seu papel constitutivo, a 
liberdade substantiva assume importância fundamental no melhoramento da vida humana quando afasta a fome, a morte prematura, o analfabetismo, a doença, entre outras mazelas. No que tange ao seu papel instrumental, importante dizer que há várias liberdades e essas são vistas como complementares umas às outras, assim como auxiliam para a capacidade geral dos indivíduos viverem com mais liberdade.

As liberdades instrumentais citadas por Sen (2000) são: liberdades políticas, facilidades econômicas, oportunidades sociais, garantias de transparência e segurança protetora. De forma resumida, as liberdades políticas dizem respeito aos direitos políticos aliados às democracias; as facilidades econômicas são as possibilidades que as pessoas têm de utilizar os recursos econômicos com a finalidade de produção, troca ou consumo; as oportunidades sociais são as prescrições que a sociedade fixa nas áreas da saúde, educação, etc. e que vão repercutir nas liberdades substantivas; as garantias de transparência são a sinceridade que as pessoas devem umas as outras, o que trará o afastamento das possibilidades de corrupção ou transações ilícitas, por exemplo; segurança protetora é o que impede que a população que se encontra vulnerável seja reduzida à miséria, passe fome ou morra, por meio de uma rede de segurança.

Essas liberdades são centrais, como se vê no trecho a seguir:

Os fins e os meios do desenvolvimento exigem que a perspectiva da liberdade seja colocada no centro do palco. Nessa perspectiva, as pessoas têm de ser vistas como ativamente envolvidas - dada a oportunidade - na conformação de seu próprio destino, e não apenas como beneficiárias passivas dos frutos de engenhosos programas de desenvolvimento. O Estado e a sociedade têm papéis amplos no fortalecimento e na proteção das capacidades humanas. São papéis de sustentação, e não de entrega sob encomenda. (SEN, 2000, p. 71).

$\mathrm{O}$ autor afirma claramente que para as pessoas tem que ser dada a oportunidade de conformar seu destino, cabendo ao Estado o fortalecimento e a proteção das capacidades humanas. A falta das capacidades faz com que os indivíduos possuam razões para se sentirem humilhados e sem esperança de atingir a vida que almejam para serem felizes.

Para tal, é preciso que as pessoas sejam alfabetizadas, estejam bem nutridas, sejam parte da vida comunitária e cívica, expressem seus pensamentos, usufruam de adequadas condições de moradia e oportunidades de trabalho, possam desfrutar da possiblidade de evolução cultural e de ter aprendizado permanente (HERRLEIN JÚNIOR, 2014). Nas palavras de $\operatorname{Sen}(2000$, p. 18), 
O desenvolvimento requer que se removam as principais fontes de privação de liberdade: a pobreza e tirania, carência de oportunidades econômicas e destituição social sistemática, negligência dos serviços públicos e intolerância ou interferência excessiva de Estados opressivos.

Quer dizer, para que os indivíduos atinjam a vida que cada um considera valiosa, não deve haver obstáculos nesse processo, daí a pobreza ter que ser vista "como privação de capacidades básicas em vez de meramente como baixo nível de renda" (SEN, 2000, p. 109). Pobreza é a carência pessoal de oportunidades para realizar alguns níveis minimamente aceitáveis de funcionamentos ${ }^{4}$.

Como as capacidades individuais dependem, de forma decisiva, das disposições econômicas, sociais e políticas, o Estado e a sociedade têm papeis amplos no fortalecimento e na proteção dessas capacidades. Assim, as capacidades dos indivíduos podem ser potencializadas pelas políticas públicas, e as políticas públicas podem ser induzidas pela capacidade de participação da sociedade. Quer dizer, o conceito de desenvolvimento humano como uma expansão das capacidades também inclui o homem como agente ativo de mudanças, não sendo ele mero beneficiário passivo dos avanços sociais e econômicos. É o que Sen (2000) denomina condição de agente de uma pessoa, ou seja, sua capacidade de provocar mudanças, de participar de ações econômicas sociais e políticas, agindo como efetivo membro da sociedade.

A educação, como também a saúde, saneamento, emprego, entre outros direitos sociais, vistos como oportunidade social e liberdade instrumental, é que vão instigar a liberdade substantiva de o indivíduo buscar uma vida melhor, uma vez que são relevantes tanto para a vida privada, como também para o envolvimento em atividades políticas e econômicas, importantes para o desenvolvimento social. Como exemplifica o autor, "o analfabetismo pode ser uma barreira formidável à participação em atividades econômicas que requeiram produção segundo especificações ou que exijam rigoroso controle de qualidade (uma exigência sempre crescente no comércio globalizado)" (SEN, 2000, p.56). A participação política, por sua vez,

\footnotetext{
${ }^{4}$ Sen (2000) reconhece uma das principais causas da pobreza é a baixa renda, mas destaca que existem vários outros fatores de ordem não-econômica na determinação do grau de pobreza de uma pessoa. Para ele, pobreza vista apenas como insuficiência de renda não dá conta da diversidade humana, pois existem diferenças de idade, sexo, talentos especiais, propensão a doenças, incapacidades, entre outros, que podem fazer com que duas pessoas tenham oportunidades de qualidade de vida muito diferentes, mesmo que compartilhem de um pacote de mercadorias idêntico.
}

Rev. de Direito Sociais e Políticas Públicas| e-ISSN: 2525-9881| Maranhão | v. 3 | n. 2 | p. 88 - 104 | Jul/Dez. 2017. 
pode ser prejudicada quando o indivíduo não tem capacidade para ler jornais ou de escrever para se comunicar com outros indivíduos em situações políticas.

Portanto, a educação é fundamental para o aproveitamento e a formação das capacidades humanas. O exercício desse direito social ou garantia protetora é que gera os instrumentos e as capacidades para o exercício da autonomia e da liberdade, tirando o indivíduo da absoluta pobreza.

Nessa perspectiva, o Estado é responsável por garantir políticas públicas, assegurando os direitos sociais dos indivíduos, como a educação, para que esses possam ser livres, como detalhado na próxima seção, em que se discorre sobre a importância do investimento estatal em educação de qualidade, em favor do desenvolvimento.

\section{ESTADO, EDUCAÇÃO E DESENVOLVIMENTO}

Um dos caminhos mais importantes para que os indivíduos tenham acesso ao conjunto de bens e serviços disponíveis na sociedade é pela educação e, por esse motivo, é tida como um "direito de todo ser humano como condição necessária para ele usufruir de outros direitos constituídos numa sociedade democrática" (GADOTTI, 2005, p. 1).

Tanto é verdade, que esse direito se encontra previsto na legislação de quase todos os países, destaca Gadotti (2005), posto que é por meio da educação que as potencialidades individuais são plenamente desenvolvidas, proporcionando ao indivíduo a aptidão para usufruir e reivindicar os seus direitos (COELHO, 2017).

Em outra via, o papel do Estado é fundamental na garantia desse direito social para assegurar oportunidades iguais para todos em liberdade, segurança, equidade e dignidade. Isto requer, impreterivelmente, o investimento na educação, não sendo aceitável sua mercantilização, a transferência desse serviço ao mercado, dando acesso a ele apenas os que podem pagar. A educação é um direito de todos.

Ao proclamar, no artigo $6^{\circ}$ da Constituição Federal de 1988, o direito à educação como o primeiro direito social e ao anunciá-la, no artigo 205, como um direito de todos e dever do Estado e da família, devendo ser promovida e incentivada com a colaboração da sociedade, objetivando "o pleno desenvolvimento da pessoa, seu preparo para o exercício da cidadania e sua qualificação para o trabalho", o Estado brasileiro reconhece a importância do tema e de assegurar aos cidadãos a dignidade da pessoa humana, garantindo os direitos básicos e 
elementares.

Esse direito à educação pertence à segunda dimensão (ou geração) dos direitos fundamentais, relacionada às liberdades positivas, reais ou concretas que, como se sabe, associam-se ao Estado do Bem-estar Social. Diferente do Estado liberal, pretensamente distanciado dos conflitos sociais, aquele assume o papel de agente conformador da realidade social. Ao serem incluídos na agenda das políticas públicas brasileiras, impõem ao Estado a obrigação de garantir aos cidadãos os direitos à saúde, educação, trabalho, alimentação, assistência social, etc, como bem ressalta Sarmento (2006, p. 19) ao lembrar as primeiras constituições que incluíram esses direitos em seu texto:

As Constituições do México (1917) e de Weimar (1919) trazem em seu bojo novos direitos que demandam uma contundente ação estatal para sua implementação concreta, a rigor destinados a trazer consideráveis melhorias nas condições materiais de vida da população em geral, notadamente da classe trabalhadora. Fala-se em direito à saúde, à moradia, à alimentação, à educação, à previdência etc.

Os direitos fundamentais de segunda geração, como o direito à educação, estão ligados à ideia de igualdade e a atuação do Estado deve orientar-se no seu atendimento de forma igualitária e justa. A igualdade aqui presente pressupõe que as pessoas colocadas em situações diferentes sejam tratadas de forma desigual. Assim, dar tratamento isonômico às partes remete à lição secular de Aristóteles de tratar igualmente os iguais e desigualmente os desiguais, na exata medida de suas desigualdades. Remete à Dworkin (2005), que defende a igualdade na distribuição dos recursos na sociedade e o princípio da responsabilidade especial, para o qual a ideia de tratamento com igual consideração e respeito é virtude soberana da comunidade política. Para ele, é dever da ordem jurídica distribuir a riqueza e só com a igualdade se pode ser livre, pois sem igualdade não existe a pré-condição necessária para se falar em liberdade, uma vez que igualdade e liberdade são conceitos que se completam. Nesse contexto, a igualdade de recursos é importante para que cada pessoa tenha oportunidade para alcançar seus objetivos.

A discussão desses direitos também remete, por fim, ao pensamento de Sen (2000), para quem o Estado deve oferecer oportunidades sociais aos cidadãos, que ganham um papel de destaque no pensamento do autor:

(...) são as disposições que a sociedade estabelece nas áreas da educação, saúde, etc., as quais influenciam a liberdade substantiva de o indivíduo viver melhor. Essas facilidades são importantes não só para a condução da vida privada (...), mas também para uma participação mais efetiva em atividades

Rev. de Direito Sociais e Políticas Públicas| e-ISSN: 2525-9881| Maranhão | v. 3 | n. 2 | p. 88 - 104 | Jul/Dez. 2017. 
econômicas e políticas. Por exemplo, o analfabetismo pode ser uma barreira formidável à participação em atividades econômicas que requeiram produção segundo especificações ou que exijam rigoroso controle de qualidade (uma exigência sempre crescente no comércio globalizado). De modo semelhante, a participação política pode ser tolhida pela incapacidade de ler jornais ou de comunicar-se por escrito com outros indivíduos em atividades políticas (SEN, 2000, p. 56).

Como já discutido na seção anterior, a falta das capacidades faz com que os indivíduos possuam razões para se sentirem humilhados, excluídos, indignos e há perda de respeito e autorrespeito. Assim, destacam Rego e Pinzani (2013), o Estado deve oferecer aos cidadãos uma educação primária gratuita pública e não pode deixar os mais pobres em uma situação de analfabetismo que inviabilize sua saída da pobreza.

Portanto, o direito à educação pressupõe igualdade, uma conquista histórica na qual se pautam os dispositivos constitucionais brasileiros que mencionam a importância dos conteúdos mínimos e formação básica comum, o que não é facilmente garantido a partir das vontades individuais. Só a intervenção de um poder maior, o Estado, viabiliza fazer desse bem um ponto de partida inicial para uma igualdade de condições. Deste modo, um dos pressupostos das diretrizes que devem nortear os conteúdos curriculares é o da igualdade de condições, assegurada e protegida pelo poder público (CF, art. 206, inciso I).

Contrários a essa tese, muitos críticos do Estado Social vêm atacando, notadamente a partir dos anos 1970, a dimensão, a estrutura, os papéis ou funções e o poder do Estado em todo mundo ${ }^{5}$. Porém, Drèze e Sen (2015) descrevem vários argumentos se opondo à proposição de privatizar a educação, ainda que não sejam contrários às instituições privadas. Para eles, essas constituem uma alternativa, mas que "não podem, de forma nenhuma, assumir o papel que as escolas públicas precisam desempenhar e vêm desempenhando na transformação da maioria dos países do mundo" (DRÈZE e SEN, 2015, p. 156-157).

\footnotetext{
${ }^{5}$ As principais críticas da direita e da esquerda ao que chamou de Estado em crise são resumidas por Bresser Pereira (1992). Na direita, destacam-se os Monetaristas, liderados por Milton Friedman, já nos anos 60, e os Neoclássicos da teoria das expectativas racionais, cujos principais expoentes são Robert Lucas e Thomas Sargent, que desenvolveram uma teoria macroeconômica alternativa ao modelo keynesiano nos anos 70. Destaca-se também a Escola da Escolha Pública, cujos principais representantes são James Buchanan (Prêmio Nobel da Economia), Mancur Olson, Gordon Tullock e William Niskanen, adeptos de uma visão da pessimista e radicalmente individualista da humanidade. Na esquerda, Bresser Pereira (1992) destaca James O'Connor e também a crítica lançada pela escola francesa de Regulação, esta porém mais voltada ao modo de regulação do que propriamente contra o Estado, cujos expoentes são Alain Lipietz, Robert Boyer e Michel Aglietta.
} 
O primeiro argumento dos autores é o de que educar e escolarizar crianças de famílias pobres seria inviável, pois as escolas privadas precisam cobrar e ter lucro para funcionar, tornando-a cara demais para as crianças com poucos recursos financeiros, deixando de ser a educação para todos.

Em segundo lugar, mesmo que o primeiro problema fosse resolvido por meio de um sistema de bolsas, por exemplo, há a questão da limitação de informação e a informação assimétrica no que diz respeito à família dos alunos, que não teriam como fazer uma escolha esclarecida para seus filhos.

Em terceiro lugar, a ausência de concorrência em certas localidades pode fazer com que as escolas só pensem em ganhar dinheiro sem oferecer qualidade de ensino em troca. Por ser particular, não quer dizer que a escola tenha melhor qualidade que a escola pública.

Em quarto lugar, a educação necessita de investimentos permanentes para a aquisição de conhecimentos específicos, assim como há externalidades características da educação escolar, o que faz com que ocorra uma ineficiência do mercado quanto à oferta e operação de serviços. Portanto, vislumbra-se uma constante necessidade de monitoramento das escolas privadas.

Por último, os pais que têm condições de pagar escola particular para seus filhos confiam mais nessas instituições por serem, teoricamente, melhores em termos de qualidade. Isso faz com que saiam das escolas públicas, justamente, os pais que mais podem contribuir em termos de reivindicações e críticas para que essas escolas se tornem mais empenhadas em alcançar maior qualidade e se subordinem à prestação de contas.

Nesses termos, o investimento estatal em políticas públicas em prol da educação é imprescindível para que o direito social à educação seja efetivado. Contudo, esse investimento não pode ser apenas quantitativo, mas qualitativo também, pois a educação deve ser para todos e com qualidade. Quer dizer, além do acesso à escola, as questões relacionadas ao fluxo escolar 6 e à qualidade do ensino devem ser observadas, contemplando as diversas dimensões do desenvolvimento humano.

É nessa perspectiva que Marta Nussbaum (2009) chama atenção para o fato de que há a educação para o lucro e a educação para a cidadania inclusiva. A educação para o lucro é mais

\footnotetext{
${ }^{6} \mathrm{O}$ fluxo escolar relaciona-se à trajetória do aluno, sua progressão entre os diferentes níveis de ensino, como as séries.
}

Rev. de Direito Sociais e Políticas Públicas | e-ISSN: 2525-9881| Maranhão | v. 3 | n. 2 | p. 88 - 104 | Jul/Dez. 2017. 
ligada à educação científica e técnica, enquanto a educação inclusiva é mais voltada para habilidades associadas às humanidades e às artes, que podem proporcionar a geração de um modelo de cultura descente e de cidadania.

Na ótica da educação para o lucro, tem-se a Teoria do Capital Humano, surgida nos anos 1950 com os estudos de Theodore Schultz e popularizada por Gary Becker, que argumenta que a educação torna as pessoas mais produtivas, aumenta seus salários e influencia o crescimento econômico. Então, o trabalho humano, quando qualificado pela educação, é uma das mais importantes fontes de ampliação da produtividade e das taxas de lucro e, consequentemente, para o aumento do PIB (VIANA; LIMA, 2010). Essa teoria coloca a educação e o desenvolvimento sob a égide da acumulação de riqueza material, do avanço tecnológico e do progresso econômico, em prol do consumo ${ }^{7}$.

Quando se fala em educação para cidadania inclusiva, a abordagem diz respeito ao desenvolvimento humano e ao alcance das capacidades humanas. Ou seja, a educação não pode se pautar pelo velho modelo de desenvolvimento baseado no crescimento econômico, pois ele não necessariamente contribui para a melhoria da qualidade de vida das pessoas. E mais, a “educação para o enriquecimento necessita de alunos dóceis, estudantes que não pensam criticamente e, particularmente, alunos que aprenderam a ignorar sistematicamente as desigualdades, que são favorecidas por uma política baseada no crescimento econômico por si só" (NUSSBAUM, 2009, p. 10). Nessa linha, a educação de qualidade deve valorizar a liberdade de pensamento e o pensamento crítico que a humanidade e as artes podem proporcionar.

A educação de qualidade, portanto, é que trará a educação para o desenvolvimento humano no momento em que os alunos têm seus sentidos enriquecidos para fomentar uma visão de humanidade, na qual os indivíduos têm direito ao desenvolvimento de forma igualitária.

Essa visão relaciona-se ao pensamento de Sen (2000), para quem o conceito de capacidades humanas não deve ser confundido com o de capital humano, embora ambos estejam relacionados às habilidades humanas. A expansão das capacidades humanas remete à

\footnotetext{
${ }^{7}$ Mais recentemente, novas categorias revitalizam essa teoria, como "empregabilidade" (capacidade pessoal de inserção e permanência no mercado de trabalho), "competências" (capacidades a serem absorvidas pelo indivíduo para desenvolver alguma ação), "flexibilidade" (capacidade de o trabalhador se adaptar às transformações inovativas do mercado), "empreendedorismo"(capacidade para criar oportunidades e formas de gerar rendimentos), entre outras.
} 
ampliação da habilidade dos seres humanos de viver em conformidade com o que valorizam. A acumulação de capital humano, por sua vez, está associada à possibilidade de aumento de produção em função de um maior treinamento, conhecimento ou esforço.

Nesse sentido, a educação desponta como um fator essencial para o desenvolvimento da sociedade e redução das desigualdades, como destaca Whestphal (2009, p. 4):

A educação deve ser tratada como um processo de humanização do sujeito, que contribua na construção de políticas que efetivem melhorias da condição humana. Ao assegurar a qualidade educacional no País, busca-se promover o crescimento da sociedade e a redução das desigualdades.

Assim, o direito à educação deve ser visto como um direito de emancipação do indivíduo, da sua formação global e de fruição da sua liberdade fática, fundamental para o exercício pleno da cidadania e para a consolidação de um Estado de raízes sociais e democráticas (COELHO, 2017).

Compete a esse Estado desenvolver políticas que possibilitem o avanço das capacidades humanas, como a educação e a saúde, defendem Drèze e Sen (2015), o que permitirá que o crescimento econômico, visto como uma ferramenta importante para melhorar a vida da população, se converta em avanço da qualidade de vida, posto que seu alcance e impacto dependem, fundamentalmente, do que é feito com seus frutos. Quer dizer, é fundamental que a receita pública por ele gerada seja investida em políticas dessa natureza.

Portanto, o Estado deve desenvolver ações para que todos tenham acesso à educação de qualidade e, consequentemente, promover a valorização do processo educacional, necessário ao desenvolvimento das capacidades humanas, o que resultará no desenvolvimento como liberdade. Esse elo entre desenvolvimento e educação abrange o papel essencial dos serviços públicos na efetivação de uma mudança educacional, em que o Estado deve participar ativamente, com a utilização maior de recursos (DRÈZE; SEN, 2015).

As experiências da Europa e dos Estados Unidos, já em meados do século XIX, mostraram a importância da educação como pilar de sustentação e como facilitadora do desenvolvimento social e econômico, influenciando grandemente as potências em ascensão da Ásia.

O Japão, relatam Drèze e Sen (2015), nessa mesma época, mostrou o papel transformador da educação escolar quando se tornou pioneiro na execução de um moderno 
desenvolvimento econômico. Em 1868, na era de restauração Meiji, apesar de o país ainda não ter atravessado o processo de industrialização ou desenvolvimento econômico moderno que a Europa já usufruía, tinha um nível de alfabetização maior. Em 1872, promulgou o Código Fundamental de Educação em que o Estado assumia um evidente compromisso público para garantir o fim do analfabetismo, em que a atuação do Estado, apesar de autoritária, garantia a universalização do ensino.

Durante a Era Meiji, entre 1868 e 1912, a importância da educação como centro das políticas públicas foi notória no início do desenvolvimento japonês, tanto que, entre 1906 e 1911, 43\% do orçamento das cidades e dos vilarejos japoneses eram investidos nessa área, o que ocasionou um grande progresso no ensino fundamental. Em 1910, os jovens japoneses eram quase que na sua totalidade alfabetizados e, em 1913, publicavam-se mais livros no Japão do que na Grã-Bretanha e nos Estados Unidos, apesar de ser um país mais pobre. Assim, o foco na educação determinou, em grande parte, "a natureza e a velocidade do progresso econômico e social do Japão" (DRÈZE; SEN, 2015, p. 131).

A estratégia japonesa para o desenvolvimento econômico na sua história moderna se deveu à ideia de que é importante que a educação escolar, em particular, e o desenvolvimento humano, em geral, voltem-se aos pobres e não apenas aos ricos.

Tempos depois, Taiwan, Hong Kong, Coreia do Sul, Cingapura e China seguiram esse exemplo no que diz respeito a incentivar a educação básica, principalmente a oferecida pelo Estado. Para eles, a educação pública foi fundamental para viabilizar sua participação na economia globalizada, o que seria muito difícil se as pessoas não fossem alfabetizadas.

Por outro lado, na Índia, mostram Drèze e Sen (2015), a evolução da educação escolar tem sido muito lenta, muito embora haja uma grande eloquência a favor dela no movimento nacionalista indiano. Em comparação com a Ásia Oriental, o país tem ficado para trás, principalmente porque as mulheres jovens indianas permanecem analfabetas ${ }^{8}$.

Mas o que faz a educação básica tão importante? Drèze e Sen (2015) apontam nove razões para isso:

\footnotetext{
${ }^{8} \mathrm{O}$ estado de Kerala, é uma exceção. Ao receber um maior incentivo à educação do que o resto do país, elevou muito mais a qualidade de vida de seus cidadãos do que os demais. A maior parte da Índia, pós-independência britânica, tinha um grau de escolaridade muito baixo, com a alfabetização de adultos na faixa de $18 \%$, o que permaneceu assim até recentemente. Até 2005/2006 cerca de 20\% das crianças indianas de seis a quatorze anos não estudavam e cerca de $10 \%$ dessas crianças nunca tinham sido sequer matriculadas em uma escola. $\mathrm{E}$ isso ocorria mais frequentemente com as meninas indianas (DRÈZE; SEN, 2015).
} 
1) A qualidade de vida é muito maior quando se sabe ler, escrever e contar, proporcionando liberdade para compreender o mundo. Ao ser bem informada, a pessoa pode se comunicar com outras e se ter plena noção da realidade. $\mathrm{O}$ analfabetismo, ao contrário, é uma prisão;

2) $\mathrm{O}$ que as pessoas aprendem ou seu nível educacional está fortemente associado às oportunidades econômicas e possibilidades de emprego;

3) O escamoteamento da voz política da população, derivado do analfabetismo, gera insegurança para a população. Isso não quer dizer que as democracias não possam ser eficazes devido à presença de analfabetos, mas que as oportunidades políticas ficam mais evidentes quando há maior empoderamento social (capacidade de ler jornais e revistas, comunicação social, etc.);

4) Muitas questões de saúde podem ser solucionadas por meio da educação básica, que pode trazer um maior entendimento sobre os problemas epidemiológicos e auxiliar na efetivação de medidas de saúde pública, como saneamento e imunização;

5) O entendimento sobre os direitos humanos é mais estimulado quando a educação é disseminada;

6) As garantias legais são melhor compreendidas e mais utilizadas, uma vez que o analfabetismo traz a falta de capacidade de compreender, praticar ou exigir os direitos legais;

7) As mulheres jovens, quando escolarizadas, melhoram sua participação nas decisões familiares, na diminuição da taxa de mortalidade infantil, entre outras questões;

8) A redução das desigualdades de classes e castas pode ser alcançada; e

9) Por fim, com uma educação agradável, de atividades criativas e bem orientadas, os jovens podem ter mais qualidade de vida.

\section{CONSIDERAÇÕES FINAIS}

A teoria desenvolvimentista de Amartya Sen trouxe uma nova roupagem para o debate sobre desenvolvimento, tendo como ponto fulcral a liberdade e o homem como centro. Assim, o crescimento econômico não pode ser um fim em si mesmo e o desenvolvimento acontece quando ocorre a expansão das liberdades reais que as pessoas podem desfrutar. Bem-estar e desenvolvimento devem estar ligados ao fortalecimento das liberdades e à melhora de vida dos indivíduos. 
Nesse processo, a felicidade humana assume importante papel nas vidas das pessoas, que devem ser vividas para que consigam realizar seus projetos de forma satisfatória. Para tanto, as fontes de privação da liberdade têm que ser retiradas, possibilitando que haja liberdade de agir do ser humano, desenvolvendo a liberdade de ser, fazer e viver em funcionamento.

Os funcionamentos são as várias coisas que uma pessoa considera valioso ter ou fazer. O conjunto alternativo de funcionamentos exequível de cada ser humano representa a sua capacidade, que é a possibilidade para ter estilos de vida diferentes. A falta de capacidades faz com que os indivíduos possuam razões para se sentirem humilhados e sem esperanças de atingir a vida que almejam para serem felizes, como ocorre quando não há oportunidade de educação, uma das fontes de privação de capacidade.

A educação, como também a saúde, entre outros direitos sociais, instiga a liberdade substantiva de o indivíduo buscar uma vida melhor, uma vez que é crucial tanto para a vida privada, como também para o envolvimento em atividades políticas e econômicas, importantes para o desenvolvimento social. Ela, bem como outros direitos sociais, gera instrumentos e capacidades para o exercício da autonomia e da liberdade, tirando o indivíduo da absoluta pobreza.

É dever do Estado garantir políticas que possibilitem o avanço das capacidades humanas, como a educação e a saúde, transformando o crescimento econômico em melhora da vida da população, dado que seu alcance e impacto dependem, em larga escala, de como seus frutos são investidos. Assim, é essencial que a receita pública por ele gerada seja investida em políticas dessa natureza.

A experiência de alguns países asiáticos, como o Japão, no qual a educação escolar voltou-se aos pobres, e não apenas aos ricos, ilustra o argumento de que ela é um importante caminho para que os indivíduos expandam essas capacidades. Como argumentam Drèze e Sen (2015), a qualidade de vida aumenta quando se sabe ler, escrever e contar, elevam-se as oportunidades econômicas e de emprego, as possibilidades de dar voz política à população, há um maior entendimento sobre os problemas epidemiológicos e chances para a efetivação de medidas de saúde pública, os direitos humanos são mais estimulados, as garantias legais são melhor compreendidas e mais utilizadas, incentiva-se a participação das mulheres jovens nas decisões familiares, dentre tantas outras razões que podem ser apontadas em favor da educação como um dos pilares do desenvolvimento. 


\section{REFERÊNCIAS}

BRESSER PEREIRA, Luiz Carlos. A crítica da direita e da esquerda a um Estado em crise. Lua Nova, São Paulo, n. 25, p. 225-250, 1992 .

COELHO, Rodrigo Batista. Direitos fundamentais sociais e políticas públicas: subjetivação, justiciabilidade e tutela coletiva do direito à educação. São Paulo: Habermann, 2017.

DRÈZE, Jean; SEN, Amartya. Glória incerta: A Índia e suas contradições. Tradução de Ricardo Doninelli Mendes, Laila Coutinho. São Paulo: Companhia das Letras, 2015.

DWORKIN, Ronald. A virtude soberana: A teoria e a prática da igualdade. Tradução de Jussara Simões. São Paulo: Martins Fontes, 2005.

FURTADO, Celso. O Mito do desenvolvimento econômico. Rio de Janeiro: Paz e Terra, 1974.

GADOTTI, Moacir. A questão da educação formal/não-formal. 2005. Disponível em: http://www.virtual.ufc.br/solar/aula_link/llpt/A_a_H/estrutura_politica_gestao_organizacional /aula_01/imagens/01/Educacao_Formal_Nao_Formal_2005.pdf. Acesso em: 30 de jun. 2017.

HERRLEIN JÚNIOR, Ronaldo. A construção de um Estado democrático para o desenvolvimento no século XXI. Texto para discussão / Instituto de Pesquisa Econômica Aplicada. Brasília : Rio de Janeiro : Ipea, 2014. Disponível em: http://www.ipea.gov.br/portal/images/stories/PDFs/TDs/td_1935.pdf. Acesso em: 22 de jun. 2017.

NUSSBAUM, Marta. Educação para o lucro, Educação para a Liberdade. Revista Redescrições - Revista on line do GT de Pragmatismo e Filosofia Norte-americana.

Ano I, número $1,2009.2$ Disponível em: http://www.gtpragmatismo.com.br/redescricoes/redescricoes/01/5Nussbaum.pdf. Acesso em: 30 de jun. 2017.

PINHEIRO, Maurício Mota Saboya: As liberdades humanas como bases de desenvolvimento: Uma análise conceitual da abordagem das capacidades humanas de Amartya Sen. Brasília: IPEA, 2012. Disponível em http://www.ipea.gov.br/portal/images/stories/PDFs/TDs/td_1794.pdf. Acesso em 02 de março de 2016.

REYES, Giovanni E. Four main theories of development: modernization, dependency, wordsystem and globalization. Nómadas. Revista Crítica de Ciencias Sociales y Jurídicas. n. 4, jul.-dez. 2001.

SACHS, Ignacy. Desenvolvimento: Includente, Sustentável, Sustentado. Rio de Janeiro. Ed. Garamond. 2004.

Rev. de Direito Sociais e Políticas Públicas| e-ISSN: 2525-9881| Maranhão | v. 3 | n. 2 | p. 88 - 104 | Jul/Dez. 2017. 
SARMENTO, Daniel. Direitos Fundamentais e Relações Privadas. $2^{\text {a }}$ Edição, Rio de Janeiro: Editora Lumen Juris, 2006.

SEN, Amartya. Desenvolvimento como Liberdade. Tradução de Laura Teixeira Motta. São Paulo: Companhia das Letras, 2000.

VIANA, Giomar; LIMA, Jandir Ferrera de. Capital humano e crescimento econômico. Interações (Campo Grande), Campo Grande , v. 11, n. 2, p. 137-148, 2010. 